\title{
Biophysical Investigation on Left Ventricular Myocytes in Rats with Experimentally Induced Diabetes
}

\author{
I. WACZULÍKOVÁ ${ }^{1}$, M. CAGALINEC ${ }^{2}$, O. ULIČNÁ ${ }^{3}$, P. SLEZÁK ${ }^{4}$, A. ZIEGELHÖFFER $^{5}$ \\ ${ }^{1}$ Department of Nuclear Physics and Biophysics, Faculty of Mathematics, Physics and Informatics, \\ Comenius University, Bratislava, Slovakia, ${ }^{2}$ Department of Pharmacology, Medical Faculty, \\ University of Tartu, Tartu, Estonia, ${ }^{3}$ Pharmacobiochemical Laboratory, Third Department of \\ Internal Medicine, Faculty of Medicine, Comenius University, Bratislava, Slovakia, ${ }^{4}$ Institute of \\ Normal and Pathological Physiology, Slovak Academy of Sciences, Bratislava, Slovakia, ${ }^{5}$ Institute \\ for Heart Research, Centre of Excellence in Cardiovascular Research, Slovak Academy of Sciences, \\ Bratislava, Slovakia
}

Received February 19, 2010

Accepted March 26, 2010

\section{Summary}

Diabetes is a recognized risk factor of heart disease. The abnormalities related to a decreased heart performance probably arise at cellular and molecular levels already in the asymptomatic phase of diabetes. However, the early alterations initiating a sequence of events that culminates in the clinical signs have not been fully elucidated yet. This review deals with some biophysical methods applied to investigation of left ventricular myocytes in rats with streptozotocin diabetes, as well as our most important findings concerning diabetes-induced cell changes which cannot be captured by other techniques. The observed decrease in sarcolemmal membrane fluidity is causatively associated with increased glycation and glycoxidation. On the other hand, an increase in the mitochondrial membrane fluidity may be attributed to augmented energy transduction through the membranes. We reported for the first time concurrent measurements of membrane potential and dynamics, and respiratory chain activities in rat heart mitochondria, as well as calcium transients in the myocytes from diabetic hearts together with the assessed quantitative relationships among these variables. We were able to detect some significant alterations that may underlie myocyte dysfunction and subsequent remodeling of the heart. We suppose that not all these changes reflect mechanisms leading to pathology; some may represent adaptive and compensatory responses to diabetes.

\begin{abstract}
Key words
Left ventricular myocytes - Membranes - Mitochondria • Biophysical properties - Fluorescence spectroscopy and microscopy
\end{abstract}

\section{Corresponding author}

I. Waczulíková, Department of Nuclear Physics and Biophysics, Faculty of Mathematics, Physics and Informatics, Comenius University, Mlynská dolina F1, 84248 Bratislava, Slovakia. E-mail: waczulikova@fmph.uniba.sk

\section{Introduction}

Diabetes mellitus (DM) is the most important risk factor of cardiovascular disease (Vozár et al. 1998, Pierce et al. 2003). Aside from hypertension and accelerated atherosclerosis, diabetic cardiomyopathy is the most prevalent. It is characterized by the long latent phase, during which the disease proceeds asymptomatically. The abnormalities related to a decreased heart performance probably arise at cellular and molecular levels already in the latent phase. However, the early alterations initiating a sequence of events that culminates in the clinical signs have not been fully clarified.

Etiologically, the main cause responsible for the 
development of heart dysfunction is sustained hyperglycaemia which promotes the formation of advanced glycation endproducts (Brownlee 1988, Baynes and Thorpe 1999, Ahmed 2005). It is assumed that glycation together with overproduction of free radicals ${ }^{1}$ are sufficient enough to explain alterations in the function of soluble and membrane-bound cellular proteins, which leads to cell dysfunctions (Brownlee 1988, Watala 1993). Since not only the proteins may be modified in such a way, it is conceivable that diabetic condition would also affect the structure, dynamic properties and related functions (Gennis 1989) of cardiac subcellular membranes.

When considering the membrane functions, the composition, rate and extent of motion of the membrane components are of high importance, since some enzymatic functions require the components to be freely diffusing within the plane of the bilayer, whereas other processes rely on constraints imposed on their mobility (Shinitzky 1984). The cells have ways how to set up physicochemical properties of the membranes to secure their functioning under changing conditions (Shinitzky 1984, Gennis 1989). Thus the major motivating factor for studying cardiac myocytes and their subcellular membranes with biophysical methods was that compromised function of the heart in DM is reflected in the changes of some physical parameters. In this way we obtained evidence supporting the notion that some molecular and cellular alterations in cardiac myocytes may represent adaptive and compensatory responses to diabetic condition and the related cardiomyopathy (Ferdinandy et al. 1998, Ravingerová et al. 2000, Ziegelhöffer 2005).

This review covers the main conventional and less conventional biophysical methods to study cell and membrane properties of left ventricular myocytes in health and disease.

\section{Methods for studying subcellular membranes}

Membrane dynamics is described by all possible modes of molecular motion among which $\mathrm{CH}_{2}$-bond vibrations, lipid rotation (about long axis), lipid and protein lateral "hopping" and protein rotation are the most considered (Gennis 1989). One should bear in mind that if the molecular motions are slow relative to the measurement, the technique yields a static, "frozen"

\footnotetext{
1 glycation-related production of free radicals is often termed "glycoxidation"
}

picture of the membrane event. Other techniques, such as the steady-state fluorescence anisotropy method, can provide a time-averaged picture of the components if they move very rapidly in relation to the time window width of the detection.

In studying cardiac cell and membrane functions in DM we have been employing two broad classes of biophysical experiments. First, the experiments using exogenous fluorescent probes (Fig. 1) (fluorescence spectroscopy and fluorescence and confocal laser scanning microscopy) to examine membrane fluidity ${ }^{2}$ and protein-lipid interactions are mentioned (Waczulíková et al. 2007). A second class of measurements entails experiments to investigate permeability, transport across the membranes and selected electrical properties of the membranes. Biophysical methods other than spectroscopic, which explore some of the membranerelated functions of cardiac myocytes, hepatocytes and their mitochondria, include voltamperometry (Uličná et al. 1999), Langendorff retrograde perfusion method (Dobaczewski et al. 2006, Waczulíková et al. 2007) and cryoelectron microscopy. The results and derived scientific conclusions have been strengthened by combining the biophysical approach with the use of techniques of biochemistry, molecular biology (Ferko et al. 2008) and biostatistics (Waczulíková et al. 2002, 2007, Waczulíková and Slezák, 2009).

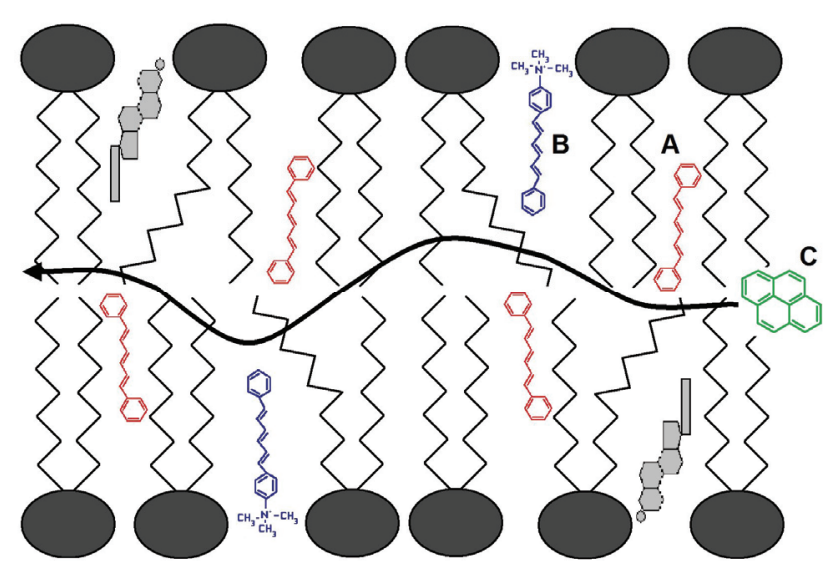

Fig. 1. Location of three of the most widely used fluorescent probes in lipid bilayers, DPH (A), TMA-DPH (B) and pyrene (C).

2 Also termed "membrane lipid packing" since the method, fluorescence anisotropy of DPH, reflects primarily structural ordering of lipid molecules in the hydrocarbon region of membranes. 


\section{Measuring of membrane fluidity}

Membrane fluidity (MF) is involved in control of many physiological processes (Shinitzky 1984, Gennis 1989). MF may be considered as a measure of the resistance to movement of various types in the membrane. The interplay between membrane lipids and proteins is crucial for membrane functions, which also predicts the cell performance. Conceivably, derangement of "normal" - optimal fluidity may be linked to some pathological conditions. Perturbations that increase the area per lipid molecule, such as higher degree of phospholipid (PL) unsaturation, lower average acyl chain length, decreased levels of cholesterol, or addition of pharmaceuticals, all result in an increase in MF (Gennis 1989, Watala 1993). Mostly, MF is measured by observing the motion of fluorescent probes which may reside in different parts, often with preferred orientations within the membrane bilayer (Fig. 1). The interpretation of experimental data depends on both, the method and probe used. The probe should be chosen so that its emission maximum is out of range of the sample autofluorescence. For more details regarding experimental protocols see Waczulíková et al. 2007, 2008, and Ziegelhöffer et al. 2009. The measured polarization $P$ or anisotropy $r$ of the light emitted by the fluorescent probe depends on the orientation of its molecular transition dipole moment with respect to the direction defined by the polarizers (parallel and perpendicular) used to make the measurements of the respective components of the intensities $\left(I_{I I}\right.$ and $\left.I_{\perp}\right)$. The values of $I_{I I}$ and $I_{\perp}$ are used to obtain the anisotropy $r$ :

$$
r=\frac{I_{I I}-I_{\perp}}{I_{I I}+2 I_{\perp}}
$$

Most measurements are made in the steady-state with continuous excitation and emission. The value of $r$ obtained from this is an average value $r_{s}$, and it can be shown that it is related to both, the lifetime of the excited state and rotational correlation time of the probe. Steadystate anisotropy measurements are thus sensitive to both the rate of motion and any constraints to that motion, so information about dynamics and molecular order gets intermixed. However, the information on structural ordering of lipid molecules prevails (Shinitzky 1984, Gennis 1989).

To evaluate MF in our experiments we used a parameter $r_{s}$ (1) of a fluorescent probe 1,6-diphenyl- 1,3,5-hexatriene (DPH) or its cationic derivative 1-[4(trimethylamino)phenyl]-6-phenyl-1,3,5-hexatriene (TMA-DPH). DPH partitions very favourably into membranes, it has an intense fluorescence, does not appear to bind to proteins, and is sensitive to the membrane physical state. Aqueous solution of DPH alone is devoid of fluorescence (Shinitzky 1984, Gennis 1989). Therefore, the fluorescence signal from labelled membranes could be ascribed solely to DPH molecules in the membrane. DPH incorporates into the hydrocarbon inside of membranes, whereas its cationic derivative TMA-DPH is located closer to the membrane surface (Fig. 1). Thus, recorded fluorescence anisotropy values have reported on MF in the respective part of the membrane lipid bilayer.

Note: in each newly designed experiment a series of measurements are performed to explore the homogeneity of the sample, since not only particle size, but also concentration influence scattering in colloidal samples. The samples must be appropriately diluted to a level at which no significant light scattering can be observed. The time course of DPH (or TMA-DPH) incorporation is obtained from consecutive measurements. A high degree of fluorescence anisotropy indicates a high degree of structural order, or lower MF (Waczulíková et al. 2007, Slezák and Šikurová 2008).

Another fluorescence probe for estimating MF is pyrene (Barenholz et al. 1996, Watala et al. 2002) (Fig. 1). To monitor pyrene mobility in the membrane or vesicle lipid bilayer, pyrene solution was introduced into the membrane suspension and incubated for $20 \mathrm{~min}$ at room temperature. Fluorescence of pyrene-labeled samples was excited at $339 \mathrm{~nm}$ and emission recorded in the range of 350-550 nm (2.5-nm slit). Pyrene mobility was reflected as the yield of the excimer formation (excimer fluorescence-to-monomer fluorescence ratio read at $395 \mathrm{~nm}$ and $470 \mathrm{~nm}$, respectively), which directly depends on the collisional rate and distances of probe molecules in the lipid bilayer.

\section{Measuring of transmembrane potential}

Transmembrane potential (TMP) is defined as the difference in the electric potentials between two aqueous phases separated by the membrane (Fig. 2) (Gennis 1989). Any charged group within the membrane will move in response to the potential difference between the two membrane surfaces, $\Delta \Phi$. If a membrane is permeable to a particular ion, e.g., $\mathrm{Na}^{+}$, and impermeable to others, then the generated potential difference at 
equilibrium is determined by the Nernst equation:

$$
\left(\psi_{S 1}-\psi_{S 2}\right)=\Delta \psi=\frac{-R T}{2.303 F Z} \log \left(\frac{\left[N a^{+}\right]_{1}}{\left[N a^{+}\right]_{2}}\right)
$$

The same equation holds for any permeable ion of valence $Z$. Experimentally, ion permeability can be increased by using specific ion carriers or ionophores such as valinomycin $\left(\mathrm{K}^{+}\right)$. The most frequent way to measure TMP in cell/membrane suspensions is to use fluorescence probes which partition in the membrane according to the Nernst equation (2).

Majority of our experiments on TMP was performed in such a way so that the data on TMP could be matched with a degree of lipid peroxidation and with the changes in MF. These studies were paralleled by modeled experiments in order to better characterize spectral behaviour of the probes used for estimating TMP [3,3'-dipentyloxacarbocyanine iodide (DiOC5(3)); 5,5',6,6'-tetrachloro-1,1',3,3'-tetraethylbenzimidazolylcarbocyanine iodide (JC-1); and 1-ethyl-2-[3-(1ethylnaphtho[1,2-d] thiazolin-2-ylidene)-2-methylpropenyl]naphtho[1,2-d]thiazolium bromide, 3,3'-diethyl9-methyl-4,5,4',5'-dibenzothiacarbocyanine (carbocyanine bromide)]. For more details regarding experimental protocols see (Waczulíková et al. 2000, 2007, Zvarík and Šikurová, 2008).

Assessment of mitochondrial oxygen consumption and phosphorylation

Oxygen consumption by isolated mitochondria was estimated by means of voltamperometry. A Clark oxygen electrode was polarized to $8 \mathrm{~V}$ and measurements were performed in a $1.6 \mathrm{ml}$ chamber with magnetic stirring, heated to $30^{\circ} \mathrm{C}$. The incubation medium contained either glutamate or succinate as substrates as well as rotenone and it was adjusted to $\mathrm{pH} 7.4$ (Rouslin and Millard 1980). Reaction was triggered by addition of mitochondria. The recorded tracings represented the oxygen consumption at basic condition in nanoatoms of oxygen per mg of protein $\left(\mathrm{nAtO} \cdot \mathrm{mg} \operatorname{prot}^{-1} \cdot \mathrm{min}^{-1}\right)$ i.e., in the presence of endogenous substrate and ADP (adenosine diphosphate) only (state 4 respiration or $\left.\mathrm{QO}_{2}(\mathrm{~S} 4)\right)$.

Oxidative phosphorylation was assessed as the ADP:O ratio (nmol ADP:nAtO) i.e., as the amount of oxygen utilized in state 3 respiration $\left(\mathrm{QO}_{2}(\mathrm{~S} 3)\right)$. This was measured in the presence of exogenous ADP added subsequently after termination of measurement of the state 4 respiration. From the obtained data the following characteristics of oxidative phosphorylation were calculated: the respiratory control index $(\mathrm{RCI})$ - i.e., the ratio of $\mathrm{QO}_{2}(\mathrm{~S} 3): \mathrm{QO}_{2}(\mathrm{~S} 4)$ and the oxidative phosphorylation rate (OPR) - velocity of the oxidative phosphorylation (nmol ADP $\cdot \mathrm{mg} \operatorname{prot}^{-1} \cdot \mathrm{min}^{-1}$ ) (Waczulíková et al. 2007). The procedures utilized in the investigation of parameters of mitochondrial function were essentially similar to those applied by Tretter and Adam-Vizi (2004).

\section{Methods for estimating cell shortening, calcium transient and volume in cardiac myocytes}

Ventricular myocytes were isolated as described previously (Cagalinec et al., 2006, Waczulíková et al. 2007). For calcium transient recording, myocytes were stained with acetoxymethyl (AM) form of the calcium indicator Fluo-3 $\left(1 \mu \mathrm{mol} \cdot \mathrm{l}^{-1}\right)$. For volumetric data acquisition, cells were stained with calcein/AM $\left(0.1 \mu \mathrm{mol} \cdot \mathrm{l}^{-1}\right)$. Cells were allowed to settle on a coverslip enabling the perfusion at a rate of $1 \mathrm{ml} \cdot \mathrm{min}^{-1}$ and field stimulation $\left(4 \mathrm{~ms}, 5 \mathrm{~V} \cdot \mathrm{cm}^{-1}\right)$. All recordings were carried out at room temperature. Fluo-3 or calcein fluorescence was collected with filter set 09 (excitation/emission $480 / 515 \mathrm{~nm}$ ) using the confocal microscope LSM 510, Zeiss equipped with a water immersion objective (40x, NA 1.2).

For cell calcium transients and cell shortening, cells were stimulated at frequency $0.5 \mathrm{~Hz}$. Rapid linescan confocal imaging protocol $(5 \mathrm{~ms})$ was used to record contractions and calcium transients quasi-simultaneously. Calcium transient amplitude (CTA) was defined as a ratio of peak (systolic) and resting (diastolic) Fluo-3 fluorescence intensity. Cell shortening was defined as a ratio of maximum cell shortening and resting cell length. 3D images of the cardiomyocytes were obtained by scanning of 2D confocal optical planes with $2 \mu \mathrm{m}$ steps in the $\mathrm{Z}$ axis using the pinhole opening of 1 Airy unit corresponding to optical slices of $0.9 \mu \mathrm{m}$. Cell volume was estimated from 3D confocal stacks using automatic cell border detection system programmed by Anton Mateašík $^{3}$ (unpublished) based on active contour algorithm (Kass et al. 1988). The algorithm was applied for every 2D slice and the area occupied by the cell was

3 RNDr. Anton Mateašík, PhD., International Laser Centre, Ilkovičova 3, 81219 Bratislava, Slovakia 


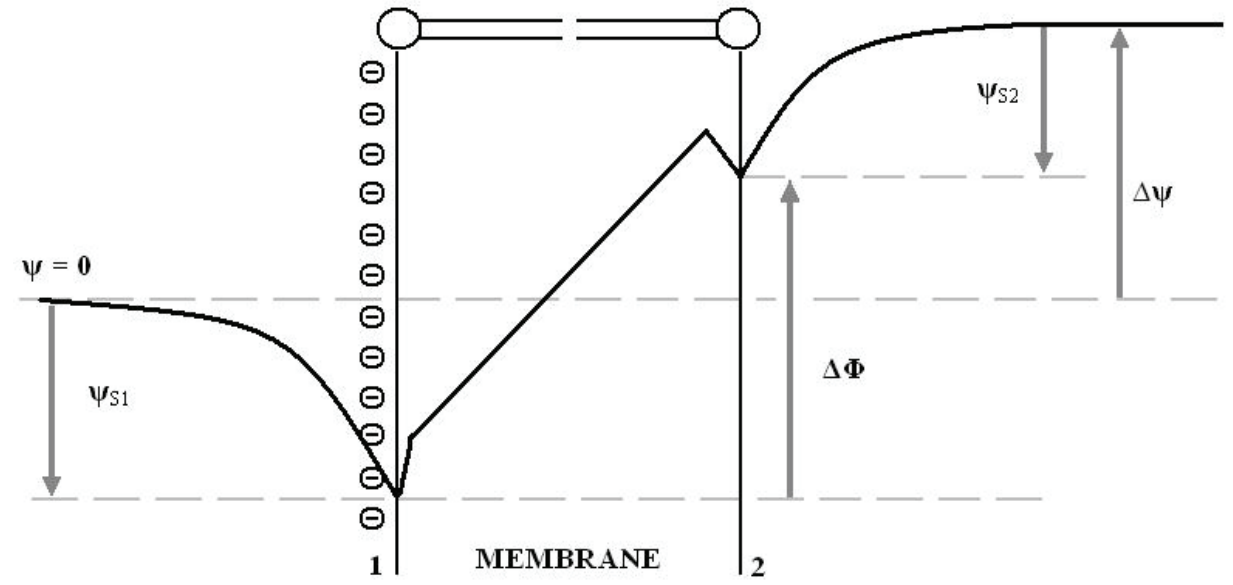

Fig. 2. Potential profile across a membrane. $\Delta \psi$ - transmembrane potential; $\psi_{\mathrm{s} 1}, \psi_{\mathrm{s} 2}$ - surface potentials; $\Delta \Phi-$ the potentials difference between the two membrane surfaces 1 and 2 .

calculated. The cell volume was defined as a sum of these areas multiplied by the optical slice thickness.

\section{Results and discussion on changes in cardiac myocytes in diabetic condition}

Experimental design, which took into account a wider range of features related to responses of sarcolemmal and mitochondrial membranes to DM, was based on simultaneous assessment of parameters obtained with relevant techniques. This approach provides matched data which can be analyzed by models considering the hierarchical structure of our data. Another way is represented by multivariable methods characterized by higher power for detecting a true effect comparing to simple bivariate analyses (Waczulíková and Slezák 2009).

Fluidity of sarcolemmal membranes assayed with DPH and TMP-DPH was decreased and its gradient across the lipid layer was reduced (Waczulíková et al. 2002, Ziegelhöffer-Mihalovičová et al. 2003). These findings can be partly attributed to the alterations in membrane composition, namely to the increased concentration of membrane cholesterol due to disorder in lipid metabolism, and partly to glycation and glycoxidation (Shinitzky 1984). The enhanced lipid peroxidation in DM (depending on the PL unsaturation index) leads to fragmentation and further cross-linking between annular or nonannular lipids and proteins.

Mitochondrial membranes differ not only in the lipid composition but also by the lipid-to-protein ratio, which could contribute to the opposite result fluidization - in DM condition. The fluidization was associated with enhanced formation of mitochondrial transition pores (MTP) which secure quick delivery of energy to cytoplasm (Ziegelhöffer 2005). The change in fluidity of the hydrophobic region of membranes is probably related to membrane shaping associated with the formation of MTP (Waczulíková et al. 2008) which was shown to be triggered by calcium (ZiegelhöfferMihalovičová et al. 1997). Since the potential link between changes in MF and the function of respiratory chain of the rat heart mitochondria in DM has not been assumed, and since the ATP synthesis in the heart mitochondria essentially depends on the TMP, the simultaneous measurement of both biophysical parameters, MF and TMP, might provide information about the capability of remodelled mitochondrial membranes to maintain energy supply in the diabetic heart (Ziegelhöffer et al. 2003). Our results showed only minor depolarization of the membranes, which indicates no irreversible opening of MTP. Statistical analysis has revealed a significant association between the increase in MF and the decrease in TMP in the mitochondria from diabetic animals. In controls no simple relationship between TMP and MF in mitochondria could be found. Further, our results showed significant decreases in the oxygen consumption in $\mathrm{QO}_{2}(\mathrm{~S} 3): \mathrm{QO}_{2}(\mathrm{~S} 4)$, in $\mathrm{RCI}$ for glutamate, and in OPR. However, the decrease in ADP:O ratio was not significant in DM (Waczulíková et al. 2007).

Based on the fact that MF, TMP, and MTP formation can be directly or indirectly influenced by intracellular calcium movements, and that TMP and calcium uptake by the mitochondria are reduced in diabetic heart (Pierce and Dhalla, 1985) we have expanded the biophysical investigation on the parameters describing calcium transients and contractility in a series of experiments on isolated left ventricular myocytes (Waczulíková et al. 2007, Ziegelhöffer et al. 2009). We found a functional impairment of the cells - shortening in DM group was significantly lower as compared to 


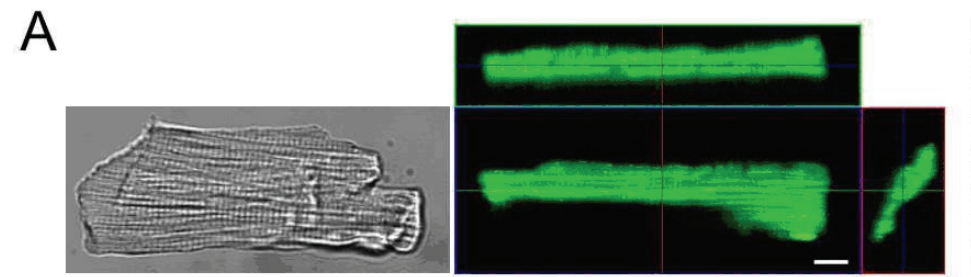

B
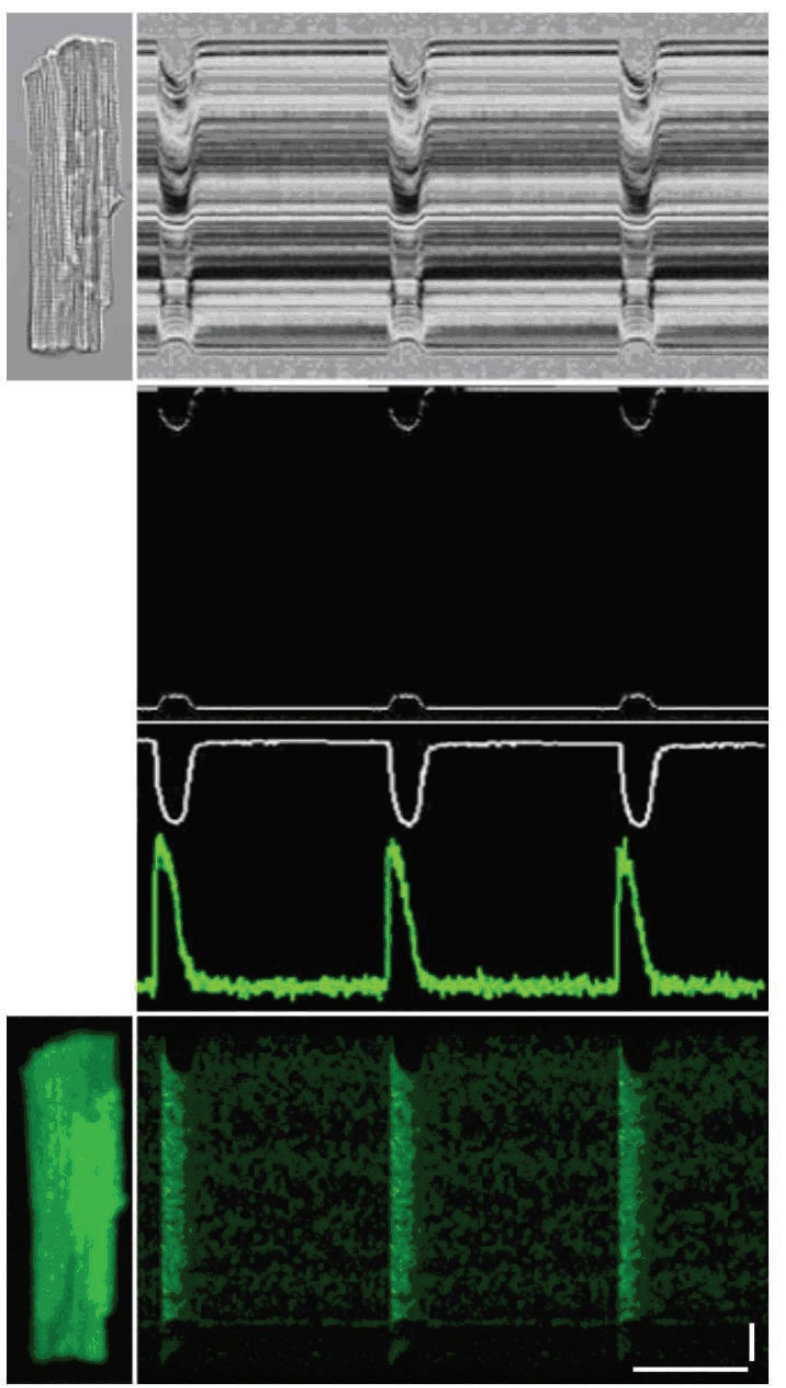

control. This lowering was not accompanied by a depressed calcium transient, moreover, no significant correlation between the cell shortening and amplitude of calcium transient was observed at the level of single cells (Fig. 3). Since the parameters of oxygen consumption except for ADP:O ratio were reduced (as mentioned above), we hypothesize that the depressed contractility observed in our experimental model of DM was a direct consequence of compromised respiratory chain functions (Waczulíková et al. 2007, Ziegelhöffer et al. 2009). However, speaking strictly in terms of significance, clinical implications of these statistically significant
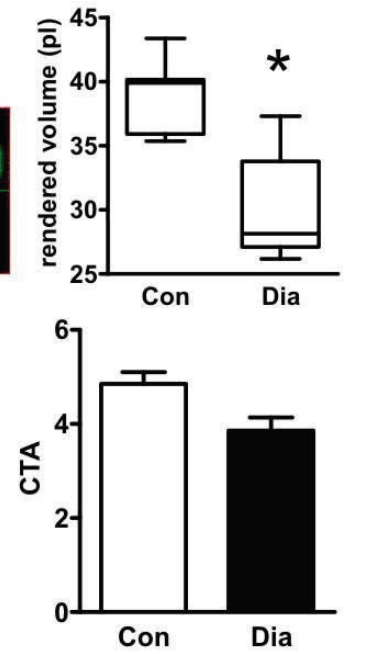

Fig. 3. A) Myocyte volume estimated from 3D confocal slides (shown as orthoslice) using active contour algorithm. Bar: $10 \mu \mathrm{m}$.

B) Left panel - simultaneous acquisition of myocyte contractions and calcium transient. Thresholding filter was used to detect myocyte boundaries in the line scan (middle part). Horizontal bar: $2 \mathrm{~s}$, vertical bar: $10 \mu \mathrm{m}$, Con - control group, Dia diabetic group, CTA -calcium transient amplitude.
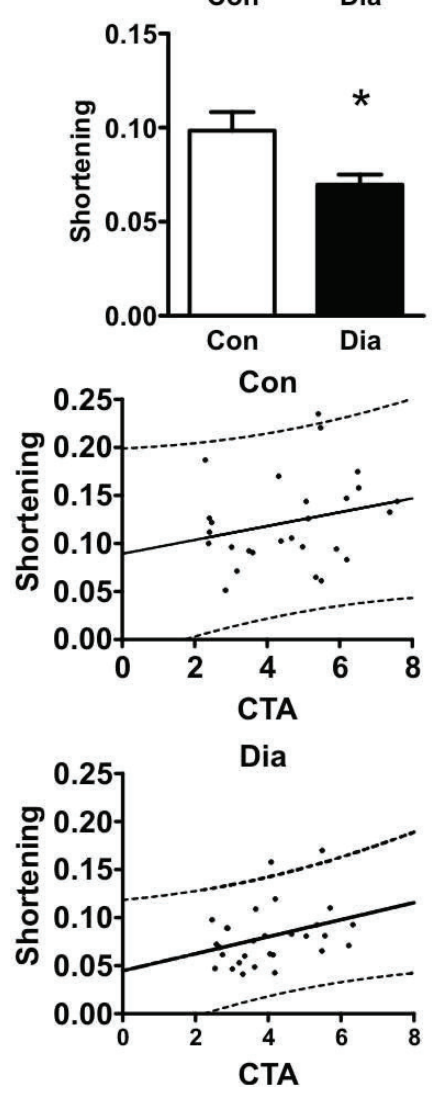

differences are not clear because the effect size cannot be quantitatively specified at the level of single cells.

\section{Concluding remarks}

In our research, we have been interested in identifying changes in those biophysical parameters which proved to be critical to the function of cardiac myocytes and their membranes in diabetes. We have reported for the first time the simultaneous measurements of membrane potential and dynamics as well as respiratory chain activities in the cardiac mitochondria 
under diabetic condition. We have shown that some of the regulatory events dictating ATP production in diabetic heart occur at the membrane level. Our results have pointed to the fact that not all changes seem to reflect pathologies, but may represent adaptive and compensatory responses to the disease. We feel it is necessary to particularly emphasize that this assumption bears some important consequences. Firstly that the preconditioning-like adaptive responses may be adequate to maintain the overall contractile performance of the diabetic heart at relatively normal levels, at least for a certain time, and secondly that the adaptive mechanisms start to develop in the cardiac myocytes. However, the question whether the observed fluidization of mitochondrial membranes and concomitant changes in membrane potential serve adaptive functions in the mitochondria of diabetic heart cannot be unambiguously resolved yet. In spite of the fact that significant gaps in understanding which events underlie adaptation of cardiomyocyte performance in disease still remain, our biophysical approach offers a new insight into these specific regulatory events.

\section{Conflict of Interest}

There is no conflict of interest.

\section{Acknowledgements}

This study was supported by the grants: APVV SK-CZ0049-07, VEGA 2/0173/08 and 1/0328/10, and a research grant UK/399/2007 from Comenius University, Bratislava, Slovakia. We would like to thank all the people who have been involved in the experiments or provided assistance, advice and support essential to the research projects.

\section{References}

AHMED N: Advanced glycation endproducts - role in pathology of diabetic complications. Diabetes Res Clin Pr 67: 3-21, 2005.

BARENHOLZ Y, COHEN T, HAAS E, OTTOLENGHI M: Lateral organization of pyrene-labeled lipids in bilayers as determined from the deviation from equilibrium between pyrene monomers and excimers. J Biol Chem 271: 3085-3090, 1996.

BAYNES JW, THORPE SR: Role of oxidative stress in diabetic complications: a new perspective on an old paradigm. Diabetes 48: 1-9, 1999.

BROWNLEE M: The pathological implications of protein glycation. Clin Invest Med 18: 275-281, 1995.

CAGALINEC M, KYSELOVIC J, BLASKOVA E, BACHAROVA L, CHORVAT D Jr, CHORVATOVA A: Comparative study of the effects of lacidipine and enalapril on the left ventricular cardiomyocyte remodeling in spontaneously hypertensive rats. J Cardiovasc Pharmacol 47: 561-570, 2006.

DOBACZEWSKI M, KAZMIERCZAK P, RAVINGEROVÁ T, ULIČNÁ O, NOCUN M, WACZULÍKOVÁ I, MARKUSZEWSKI L, WATALA C: Ex vivo detection of rat coronary endothelial dysfunction in diabetes mellitus: Methodological considerations. Methods Find Exp Clin Pharmacol 28: 507-513, 2006.

FERDINANDY P, SZILVASSY Z, BAXTER GF: Adaptation to myocardial stress in disease states: is preconditioning a healthy heart phenomenon? Trends Pharmacol Sci 19: 223-229, 1998.

FERKO M, HABODÁSZOVÁ D, WACZULÍKOVÁ I, MUJKOSOVÁ J, KUCHARSKÁ J, SIKUROVÁ L, ZIEGELHOFFER B, STYK J, ZIEGELHOFFER A: Endogenous protective mechanisms in remodeling of rat heart mitochondrial membranes in the acute phase of streptozotocin-induced diabetes. Physiol Res 57: 67-73, 2008.

GENNIS RB: Biomembranes. Molecular Structure and Function. CR CANTOR (ed.), Springer-Verlag, New York, $1989,533 \mathrm{pp}$.

KASS M, WITKIN A, TERZOPOULOS D: Snakes: active contour models. Int J Comput Vision 1: 321-331, 1988.

PIERCE GN, DHALLA NS: Heart mitochondrial function in chronic experimental diabetes in rats. Can J Cardiol 1: 48-54, 1985.

PIERCE GN, NAGANO M, ZAHRADKA P, DHALLA NS (eds.), Atherosclerosis, Hypertension and Diabetes. Kluwer Academic Publishers, Norwell, MA, USA, 2003, 520 pp. 
RAVINGEROVA T, PANCZA D, VOLKOVOVA K, DZURBA A, STETKA R, ZIEGELHÖFFER A, STYK J: Response to myocardial ischemia is modulated in diabetic rat heart: adaptation to disease? Exp Clin Cardiol 3: $122-128,2000$.

ROUSLIN W, MILLARD RW: Canine myocardial ischemia: defect in mitochondrial electron transfer complex I. $J$ Mol Cell Cardiol 12: 639-645, 1980.

SHINITZKY M: Membrane Fluidity and Cellular Functions. Physiology of Membrane Fluidity. M. SHINITZKY (ed.), CRC Press, Boca Raton, 1984, pp 1-184.

SLEZÁK P, S̆IKUROVÁ L: Influence of storage of insulated erythrocytes membranes on membrane. In: Proceedings of the 3rd Slovak Biophysical Symposium, Bratislava, 2008, pp 65-66.

TRETTER L, ADAM-VIZI V: Mechanisms for endogenous production and elimination of reactive oxygen species in mitochondria. EJB, The FEBS J 271 (Suppl. I): 198, 2004.

ULIČNÁ O, ZLATOŠ L, HOLZEROVÁ J, KVASZOVÁ E, ČÁRSKY J, GVOZDJAKOVÁ A, KUCHARSKÁ J, BADA V: The effect of neonatally induced streptozotocine diabetes on hepatic mitochondrial bioenergetics in adult rats. Bratisl Lek Listy 100: 5-11, 1999.

VOZÁR J, KREZE A, KLIMEŠ I. (eds.), Diabetes Mellitus. Slovak Academic Press, Bratislava, 1998, pp 1-286.

WACZULÍKOVÁ I, ŠIKUROVÁ L, BRYSZEWSKA M, REKAWIECKA K, ČÁRSKY J, ULIČNÁ O: Impaired erythrocyte transmembrane potential in diabetes mellitus and its possible improvement by resorcylidene aminoguanidine. Bioelectrochemistry 52: 251-256, 2000.

WACZULÍKOVÁ I, ZIEGELHÖFFER A, ORSZÁGHOVÁ Z, ČÁRSKY J: Fluidising effect of resorcylidene aminoguanidine on sarcolemmal membranes in streptozotocin-diabetic rats: Blunted adaptation of diabetic myocardium to Ca2+ overload. J Physiol Pharmacol 53: 727-739, 2002.

WACZULÍKOVÁ I, HABODASZOVÁ D, CAGALINEC M, FERKO M, ULIČNÁ O, MATEAŠIK A, ŠIKUROVÁ L, ZIEGELHÖFFER A: Mitochondrial membrane fluidity, potential, and calcium transients in the myocardium from acute diabetic rats. Can J Physiol Pharmacol 85: 372-381, 2007.

WACZULÍKOVÁ I, KINCELOVÁ D, CAGALINEC M, ULIČNÁ O, FERKO M, MUJKOŠOVÁ J, RAVINGEROVÁ T, ZIEGELHÖFFER A, ŠIKUROVÁ L: Biophysical methodology helps to provide insight into the changes in heart caused by streptozotocin-induced diabetes and hypertension. In: Experimental Approaches in Basic Research and Diagnostic of Diseases: Tailoring the Treatment. N TRIBULOVÁ, L' OKRUHLICOVÁ, J SLEZÁK (eds), VEDA, Bratislava, 2008, pp 91-103.

WACZULÍKOVÁ I, SLEZÁK P: Statistics in Medical Research. Radiology IV: Uroradiology (in Slovak). Veda, Bratislava, 2009. ISBN 978-80-224-1102-8.

WATALA C: Altered structural and dynamic properties of blood cell membranes in diabetes mellitus. Diabetic Med 10: 13-20, 1993.

WATALA C, WACZULÍKOVÁ I, WIECLAWSKA B, ROZALSKI M, GREŠNER P, GWOŹDZIŃSKI K, MATEAŠIK A, ŠIKUROVÁ L: Merocyanine 540 as a fluorescent probe of altered membrane phospholipid asymmetry in activated whole blood platelets. Cytometry 49: 119-123, 2002.

ZIEGELHÖFFER A, WACZULÍKOVÁ I, RAVINGEROVÁ T, ZIEGELHÖFFER-MIHALOVIČOVÁ B, NECKÁŘ J, STYK J: Augmented energy transfer in rat heart mitochondria: compensatory response to abnormal household of energy in acute diabetes. In: Atherosclerosis, Hypertension and Diabetes. GN PIERCE, M NAGANO, P ZAHRADKA, NS DHALLA, KLUWER (eds), Academic Publishers, Boston, 2003, pp 439-453.

ZIEGELHÖFFER A: Endogenous protective mechanisms in the heart triggered by acute streptozotocin-diabetes. In: Experimental Hypertension and Ischemic Heart Disease. L BACHÁROVÁ, J KYSELOVIČ, J SLEZÁK, (eds), VEDA, Publishing House of the Slovak Academy of Sciences, Bratislava, 2005, pp 193-208.

ZIEGELHÖFFER A, WACZULÍKOVÁ I, FERKO M, KINCELOVÁ D, ZIEGELHÖFFER B, RAVINGEROVÁ T, CAGALINEC M, SCHÖNBURG M, ZIEGELHÖFFER T, ŠIKUROVÁ L, ULIČNÁ O, MUJKOŠOVÁ J: Calcium signaling-mediated endogenous protection of cell energetics in the acutely diabetic myocardium. Can J Physiol Pharmacol 87: 1083-1094, 2009. 
ZIEGELHÖFFER-MIHALOVIČOVÁ B, OKRUHLICOVÁ L', TRIBULOVÁ N, RAVINGEROVÁ T, VOLKOVOVÁ K, ŠEBOKOVÁ J, ZIEGELHÖFFER A: Mitochondrial contact sites detected by creatine phosphokinase activity in the hearts of normal and diabetic rats: Is the contact sites formation a calciumdependent process? Gen Physiol Biophys 16: 329-338, 1997.

ZIEGELHÖFFER-MIHALOVIČOVÁ B, WACZULÍKOVÁ I, ŠIKUROVÁ L, STYK J, ČÁRSKY J, ZIEGELHÖFFER A: Remodeling of the sarcolemma in diabetic rat hearts: The role of membrane fluidity. Mol Cell Biochem 249: 175-182, 2003.

ZVARÍK M, ŠIKUROVÁ L: Monitoring possibilities of the mitochondrial membrane potential by a thiadicarbocyanine tribromide fluroscent probe. In: Proceedings of the 3rd Slovak Biophysical Symposium. Bratislava, 2008, pp 51-52. 